\title{
High-Resolution Melting Is a Sensitive, \\ Cost-Effective, Time-Saving Technique for BRAF V600E Detection in Thyroid FNAB Washing Liquid: A Prospective Cohort Study
}

\author{
Marco Marino ${ }^{a, b}$ Maria Laura Monzani ${ }^{a, d} \quad$ Giulia Brigante $^{a, d}$ Katia Cioni ${ }^{a, d}$ \\ Bruno Madeo ${ }^{a, d}$ Daniele Santia, d Antonino Maiorana ${ }^{c}$ Stefania Bettellic \\ Valeria Moriondo ${ }^{a, b} \quad$ Elisa Pignatti ${ }^{a, b} \quad$ Lara Bonacini ${ }^{a, d}$ Cesare Carani ${ }^{a}$ \\ Vincenzo Rochira ${ }^{a, d}$ Manuela Simoni ${ }^{a}$ b, d

\begin{abstract}
a Unit of Endocrinology, Department of Biomedical, Metabolic and Neural Sciences, ${ }^{b}$ Center for Genomic Research and ${ }^{\mathrm{C} D e p a r t m e n t}$ of Diagnostic and Clinical Medicine and Public Health, University of Modena and Reggio Emilia, and ${ }^{\mathrm{d}}$ Azienda USL of Modena, Modena, Italy
\end{abstract}

\section{Key Words}

BRAF gene $\cdot$ High-resolution melting $\cdot$ Washing liquids of fine needle aspiration biopsy . Papillary thyroid cancer . Thyroid

\begin{abstract}
Objective: The diagnostic accuracy of thyroid fine needle aspiration biopsy (FNAB) can be improved by the combination of cytological and molecular analysis. In this study, washing liquids of FNAB (wFNAB) were tested for the BRAF V600E mutation, using the sensitive and cost-effective technique called high-resolution melting (HRM). The aim was to demonstrate the feasibility of BRAF analysis in wFNAB and its diagnostic utility, combined with cytology. Design: Prospective cohort study. Methods: 481 patients, corresponding to 648 FNAB samples, were subjected to both cytological (on cells smeared onto a glass slide) and molecular analysis (on fluids obtained washing the FNAB needle with $1 \mathrm{ml}$ of saline) of the same aspiration. BRAF V600E analysis was performed by HRM after methodological validation for application to wFNAB (technique sensitivity: 5.4\%). Results: The cytologi-
\end{abstract}

cal results of the FNAB were: $136(21 \%)$ nondiagnostic (THY1); 415 (64\%) benign (THY2); 80 (12.4\%) indeterminate (THY3); 9 (1.4\%) suspicious for malignancy (THY4); 8 (1.2\%) diagnostic of malignancy (THY5). The BRAF V600E mutation was found in 5 THY2, 2 THY3, 6 THY4 and 6 THY5 samples. Papillary carcinoma diagnosis was histologically confirmed in all $B R A F+$ thyroidectomized patients. BRAF combined with cytology improved the diagnostic value compared to cytology alone in a subgroup of 74 operated patients. Conclusions: HRM was demonstrated to be a feasible method for BRAF analysis in wFNAB. Thanks to its sensitivity and cost-effectiveness, it might be routinely used on a large scale in clinical practice. In perspective, standby wFNAB samples could be analyzed a posteriori in case of indeterminate cytology and/ or suspicious findings on ultrasound.

(C) 2015 European Thyroid Association Published by S. Karger AG, Basel

M.M. and M.L.M. contributed equally to the study. This work has been awarded with a poster price at the 16th European Congress of Endocrinology, Wrocklaw, May 3-7, 2014.

$\begin{array}{ll}\text { KARGER 125/s } & \begin{array}{l}\odot 2015 \text { European Thyroid Association } \\ \text { Published by S. Karger AG, Basel } \\ \text { 2235-0640/15/0042-0073 } \$ 39.50 / 0\end{array} \\ \begin{array}{l}\text { E-Mail karger@karger.com } \\ \text { www.karger.com/etj }\end{array} & \end{array}$

Vincenzo Rochira, MD, PhD

Unit of Endocrinology, NOCSAE

Via Giardini 1355

IT-41126 Modena (Italy)

E-Mail rochira.vincenzo@ unimore.it 


\section{Introduction}

$B R A F$ point mutations are common in papillary thyroid cancer (PTC) [1]. The most frequent missense mutation BRAF V600E is due to the replacement of valine by glutamic acid (NM_004333.4), resulting in a constitutive MEK/ERK activation, with consequent promotion of cell proliferation and tumor growth [1-3].

In the thyroid, BRAF mutations exclusively occur in PTC and PTC-derived anaplastic cancer, but not in follicular neoplasms [4]. Thus, BRAF V600E can be considered a diagnostic marker of PTC [1].

The wide clinical use of ultrasound (US) [5] allows detecting an increasing number of nodules that often require fine needle aspiration biopsy (FNAB) for ruling out thyroid cancer [6]. As the diagnostic value of FNAB is limited by the occurrence of false-negative (FN) results and diagnosis belongs to the indeterminate cytological category (15-25\%) $[7,8]$, ancillary tests are required to improve diagnostic accuracy and patient treatment outcomes $[7,8]$. For this purpose, the analysis of FNAB specimens for BRAF V600E was demonstrated to be feasible [9], increasing the diagnostic value of FNAB compared with cytology alone [7-10].

Formerly, the molecular marker BRAF V600E was tested on FNAB specimens [11] or on cells scraped from slides [12], and only recently on washing liquids of FNAB (wFNAB), obtained by washing the FNAB needle with sterile saline solution [13-15]. Until now, wFNAB has been analyzed by PCR [13], dual priming oligonucleotide [15] and amplification refractory mutation system PCR [14]. Nikiforov et al. [16] tested samples stored in an acid preservative solution for $B R A F$ mutation by fluorescence melting curve analysis.

In the literature, the BRAF V600E mutation was found in 3-5\% of benign nodules at cytology and demonstrated a high specificity for PTC $[13,15]$, thus supporting a role in the rule-in approach to FNAB [7].

In the present study, we specifically searched for the $B R A F$ V600E mutation in wFNAB samples, independently from cytological results, using an accurate and sensitive method such as the high-resolution melting (HRM) technology, validated ad hoc. Our first target was to set up HRM, applied to wFNAB, for the detection of BRAF $\mathrm{V} 600 \mathrm{E}$ and to assess the method sensitivity. The second aim was to validate it on a prospective cohort of patients undergoing $\mathrm{FNAB}$, in order to demonstrate whether $B R A F$ mutation analysis in wFNAB is a convenient, additional diagnostic tool, useful in clinical practice, allowing the simultaneous assessment of molecular and cytological features of the same FNABs.

\section{Subjects and Methods}

\section{Patients}

With a prospective cohort study design, in 16 months we enrolled 485 patients, undergoing diagnostic examination at the Endocrinology Unit of the University of Modena and Reggio Emilia (fig. 1). The Local Ethic Committee approved this study (Protocol No.: 122/08), and each subject provided written informed consent.

Four patients were excluded because of the lack of cytological classification data. Finally, 481 patients were considered: 117 men (24\%) and 364 women (76\%). Since some patients presented more than 1 nodule, a total of 648 thyroid biopsies were analyzed (fig. 1).

\section{FNAB Procedure}

Seven experienced operators performed US-assisted (Siemens Acuson Antares ${ }^{\circledR}$, Philadelphia, Pa., USA; $10 \mathrm{MHz}$-linear scanner, $B$ mode) FNAB with a 22- to 23-gauge needle. FNAB samples were expelled onto glass slides, smeared, fixed and stained according to standard procedures.

$w F N A B$ samples were obtained washing out the needle with $1 \mathrm{ml}$ of sterile saline solution and collecting the remaining material into a $2-\mathrm{ml}$ sterile tube. This material was stored at $-20^{\circ} \mathrm{C}$ for future molecular analyses.

\section{Cytological Analysis}

According to the American Thyroid Association guidelines [8], the cytological report resulted in the following five different classes: THY1, nondiagnostic; THY2, benign; THY3, indeterminate; THY4, suspicious for malignancy; THY5, diagnostic of malignancy. The cytological samples associated with BRAF positivity in wFNAB were re-reviewed by the same pathologist (A.M.).

\section{Cell Lines}

For HRM validation, we used both negative $(\mathrm{C}-)$ and positive controls (C+) for BRAF V600E mutation. C- was represented by germline DNA, extracted from whole peripheral blood of patients with documented normal thyroid US. DNA extracted from two cell lines of metastatic BRAF mutated melanoma, WM266-4 and Lu1205, represented C+.

\section{DNA Isolation}

Somatic DNA was extracted from wFNAB using a lysis buffer and proteinase K (Roche Diagnostics, Mannheim, Germany). Genomic DNA of negative controls was extracted using the Nucleon BACC1 Genomic DNA Extraction Kit (GE Healthcare, Life Sciences, Little Chalfont, UK). DNA quality and quantity were assessed by a spectrophotometer (Nanodrop ND-1000, Thermo Fisher Scientific, NanoDrop, Wilmington, Del., USA).

HRM Analysis

Primer pairs, flanking the site of BRAF c.1799 (forward 5' -AGG TGATTTTGGTCTAGC- $3^{\prime}$ and reverse $5^{\prime}$-ATCCAGACAACT GTTCAA-3'), were designed with Beacon Designer 7.9 (Premier Biosoft International, Palo Alto, Calif., USA). 20 ng of DNA was enough to discriminate the samples V600E+, wild-type and V600D+ (fig. 2).

HRM analysis correctly classified all samples and was randomly confirmed by direct sequencing in 23/648 (3.5\%) samples, both $B R A F+$ and $B R A F-$, previously screened by HRM. Additionally, randomly chosen $30 / 648$ samples, both $B R A F+$ and $B R A F-$, were
Marino et al. 


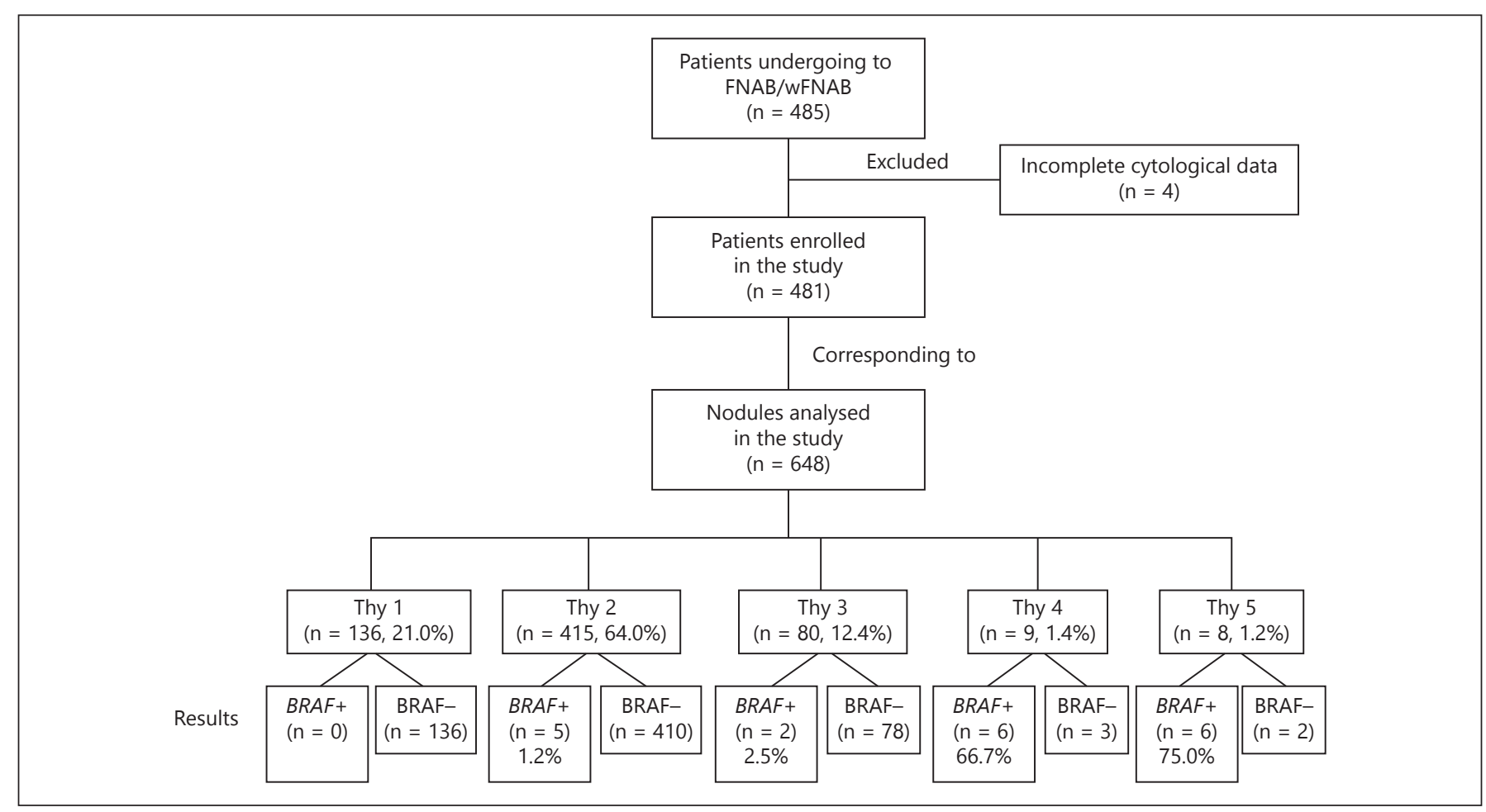

Fig. 1. Study design. $B R A F+=$ Positivity of $B R A F$ mutation by HRM; $B R A F-=$ wild-type sample by HRM; THY1 = nondiagnostic; THY2 = benign; THY3 = indeterminate; THY4 = suspicious for malignancy; THY5 = diagnostic of malignancy.

run 3 times in HRM, using independent reaction plates, to confirm the method reproducibility.

The sensitivity threshold of the HRM protocol was assessed analyzing through HRM serial DNA dilutions, obtained mixing the DNA of the WM266-4 cell line (V600D+) with the DNA of a $B R A F$ - control. The HRM analysis detected correctly the BRAF mutation in very diluted samples down to samples with $5.4 \%$ of positive DNA. Therefore the validated technique is able to detect a point mutation when the mutated DNA represents at least $5.4 \%$ of the sample. These data were confirmed by pyrosequencing.

HRM raw data (preliminary melting curves) were analyzed using the specific software CFX Manager and Precision Melt Analysis (Bio-Rad Laboratories, Hercules, Calif., USA).

\section{Pyrosequencing}

Pyrosequencing with a Therascreen BRAF Pyro Kit on the PyroMark Q96 ID instrument (Qiagen GmbH, Hilden, Germany) was used to confirm HRM results in a subset of specimens.

Direct Sequencing

Direct sequencing was used to assess the mutational status of $B R A F$ in negative and positive controls (protocol not shown).

\section{Assessment of Sample Stability}

Once thawed, the somatic DNA was extracted from wFNAB samples, immediately analyzed by $\mathrm{HRM}$ and refrozen at $-20^{\circ} \mathrm{C}$. The stability over time of the refrozen DNA was tested in HRM after years, obtaining the same excellent results (fig. 3).

$B R A F$ V600E in Washing Liquid of Thyroid FNAB

\section{Results}

At cytological analysis, the 648 FNAB samples were classified as follows: THY1, 136 (21\%); THY2, $415(64 \%)$; THY3, 80 (12.4\%); THY4, 9 (1.4\%); THY5, 8 (1.2\%) (fig. 1).

Overall, 629 (97\%) wFNAB samples showed a wildtype melting curve, while 19 (3\%) samples were $B R A F+$. None of the 136 THY1 samples was $B R A F+$, while 5 THY2 (1.2\%), 2 THY3 (2.5 \%), 6 THY4 (66.7\%) and 6 THY5 (75\%) samples were found to be $B R A F+$, respectively (fig. 1). The distribution of the $19 B R A F+$ in the cytological categories was: THY2, 26.3\%; THY3, 10.5\%; THY4, $31.6 \%$, and THY $5,31.6 \%$.

Among THY2 nodules, 5 wFNAB samples (identified as s1B, s2, s3, s4 and s5) of 5 different patients (respectively patients $1,2,3,4,5$ ) were $B R A F+$, and 4 of them were verified by pyrosequencing on scraped cells from glass slides (sFNAB; table 1 ).

Considering patient 1,2 different nodules (s1A and s1B) underwent FNAB. At cytological examination, s1A was THY3 (presence of nests of epithelial cells with microfollicular architecture), while s1B was THY2 (no 

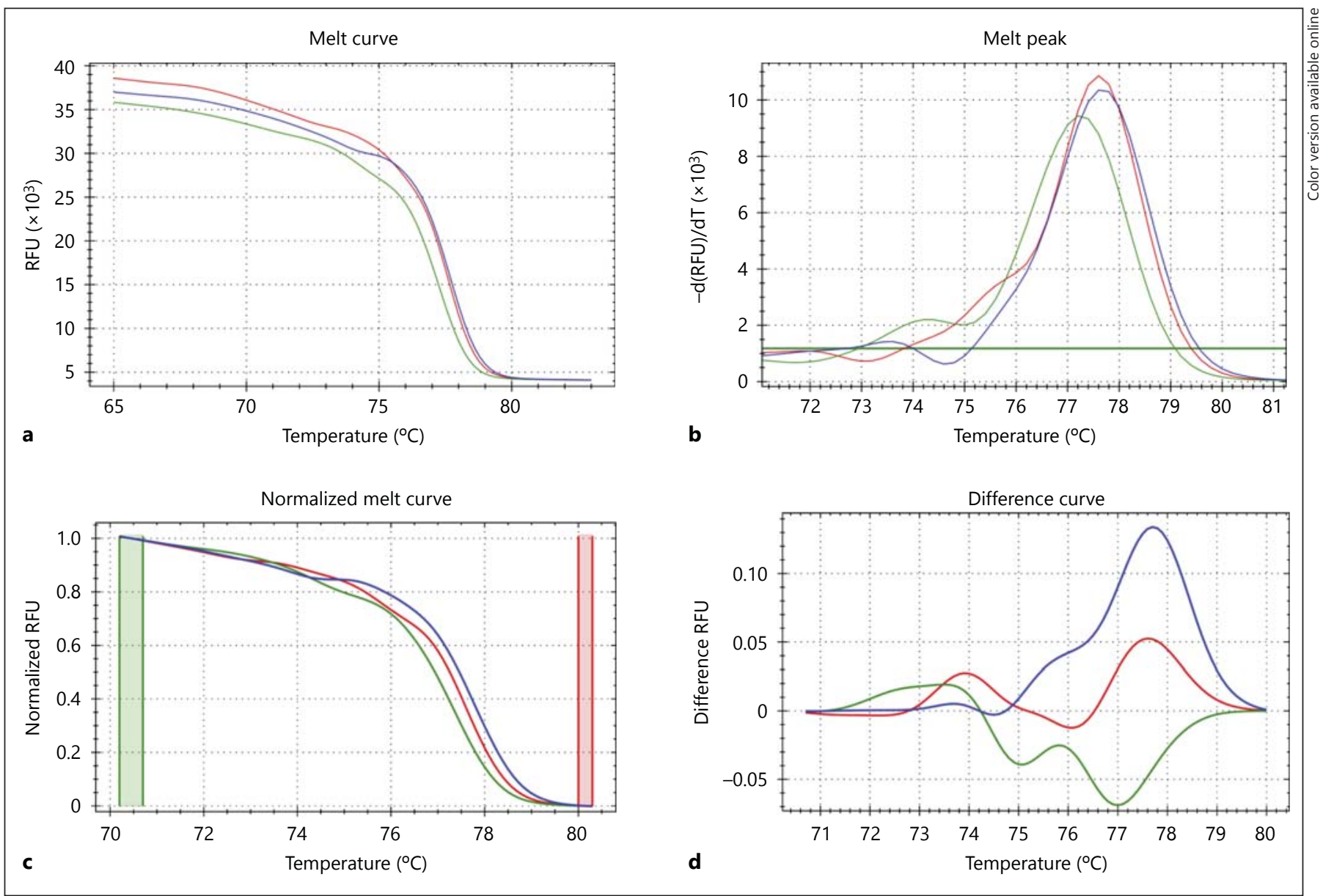

Fig. 2. Different clusters of HRM melting curves. The three different clusters, present in the picture, are obtained by the amplification and HRM analysis of exon 15 of the BRAF gene. While the DNA of V600D+ and V600E+ controls (green and red curves in a-d, respectively) were extracted by a commercial kit, the somatic DNA from wFNAB was obtained by pelletting the cells and by using $60 \mu \mathrm{l}$ of lysis buffer $(50 \mathrm{~mm}$ Tris- $\mathrm{HCl}$ at $\mathrm{pH} 8.5,1 \mathrm{~mm}$ EDTA, $0.5 \%$ Tween 20 and sterile water) with $20 \mu$ lof proteinase $\mathrm{K}(10 \mathrm{mg} /$ $\mathrm{ml}$; Roche Diagnostics), and by incubating the samples at $56^{\circ} \mathrm{C}$ overnight and then at $95^{\circ} \mathrm{C}$ for $20 \mathrm{~min}$ to have a high yield from few cells also. The cluster of BRAF- samples is represented by a blue curve. All HRM analyses were performed using the SSO Fast Eva Green Supermix 2× (Bio-Rad Laboratories) and the same fol-

cellular atypia). Surprisingly, s1B, i.e. the cytologically benign sample, was $B R A F+$ (table 1 ) accordingly with its US features (microcalcifications and ill-defined margins). In consideration of the US features, cytological finding and BRAF positivity, the patient underwent total thyroidectomy resulting in a papillary thyroid microcarcinoma in the THY2 nodule (s1B) and the presence of follicular hyperplastic architecture in the other nodule (s1A) at histology.

lowing protocol: $98^{\circ} \mathrm{C}$ for $2 \mathrm{~min}, 44 \mathrm{cycles}$ of $3 \mathrm{~s}$ at $98^{\circ} \mathrm{C}$ and $30 \mathrm{~s}$ at $56.1^{\circ} \mathrm{C}, 1 \mathrm{cycle}$ at $98^{\circ} \mathrm{C}$ for $30 \mathrm{~s}$ and $65^{\circ} \mathrm{C}$ for $1 \mathrm{~min}$ and $30 \mathrm{~s}$, a progressive denaturation from 65 to $83^{\circ} \mathrm{C}$, increasing the temperature by $0.2^{\circ} \mathrm{C}$ every $10 \mathrm{~s}$ and recording the fluorescence intensity for each increment. $-\mathrm{d}(\mathrm{RFU}) / \mathrm{dT}=$ Negative derivative $(-\mathrm{d})$ of relative fluorescence units (RFU) over temperature (dT). a Original melting curves of V600D+, V600E+ and wild-type samples in green, red and blue, respectively. b Melting peaks showing the three characteristic shapes of V600D+ (green), V600E+ (red) and wild-type (blue) samples. c Normalization of V600D+ (green), V600E+ (red) and wild-type (blue) melting curves. d The differences between the three normalized curves, belonging to V600D+ (green), V600E+ (red) and wild-type (blue) samples.

In patient 2, the presence of the BRAF V600E mutation at HRM analysis was repeatedly (3 times) verified in wFNAB and also confirmed by pyrosequencing on sFNAB. Despite THY2, US features were (hypoechoic nodule) suspicious for malignancy, and the patient underwent total thyroidectomy resulting in a partially cystic PTC at histology (table 1).

In patient 3, BRAF V600E positivity, at HRM on wFNAB, was confirmed by pyrosequencing on $\mathrm{sFNAB}$ 

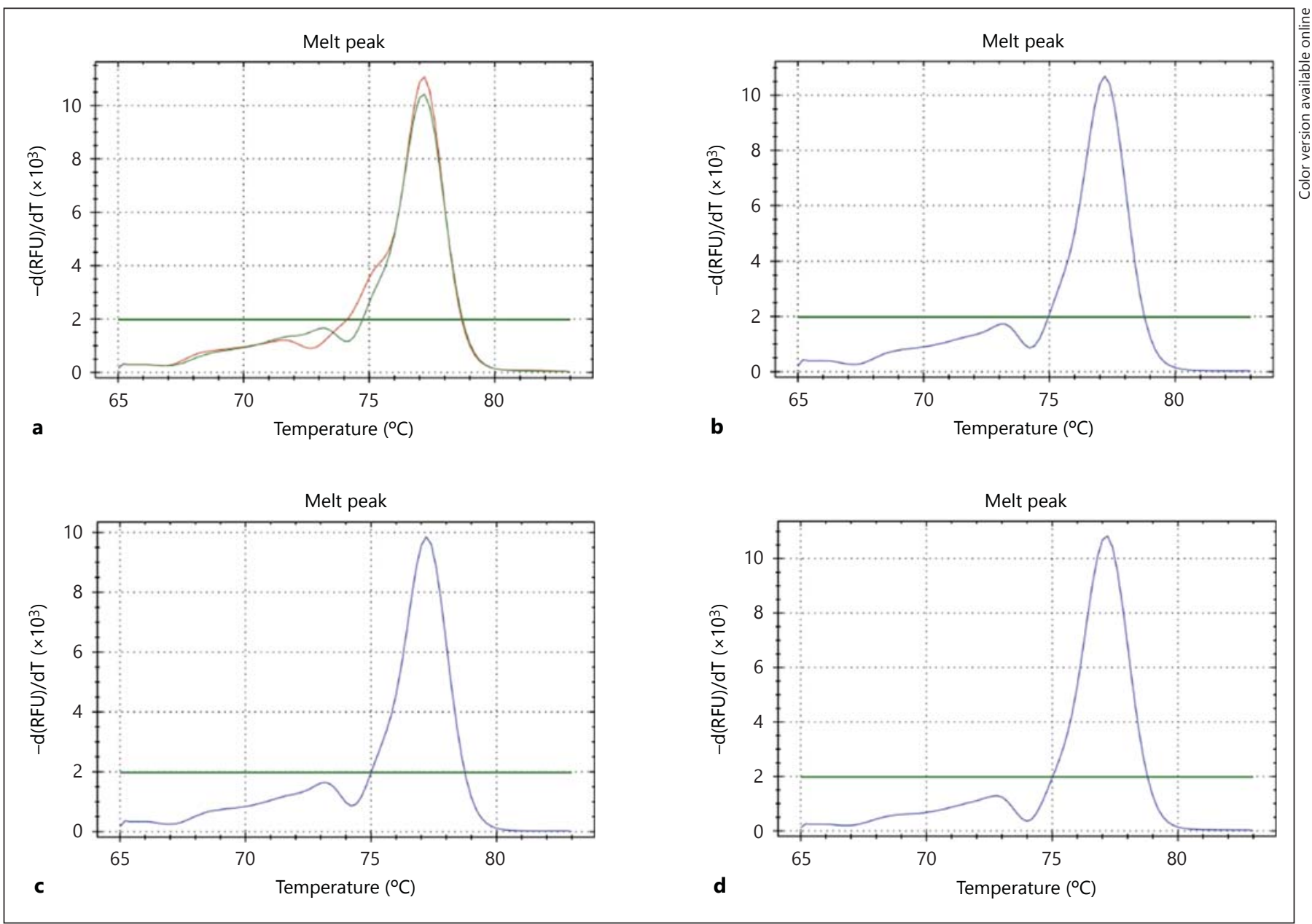

Fig. 3. Test of sample stability over time and reliability of the HRM results. We decided to test the stability of the refrozen DNA after a lapse of time by HRM analysis. Thus, 3 groups of samples, thawed and tested by HRM for the first time in April 2012, 2013 and 2014 were rethawed in May 2014 and reanalyzed by HRM, obtaining for all samples good amplification curves and excellent melting profiles, comparable to the control profiles, also confirming the same

(table 1). On US, this nodule appeared calcified. Because of the BRAF positivity, the patient underwent total thyroidectomy, and a classical variant of PTC was histologically documented.

Patient 4 had a multinodular goiter, with a nodule hypoechoic with halo. The BRAF V600E mutation was detected by HRM analysis on the wFNAB sample, but pyrosequencing did not confirm this result on the wFNAB sample (table 1). The discrepancy between HRM and pyrosequencing on $\mathrm{wFNAB}$ prompted us to test also the sFNAB sample that showed the wild type in HRM, pyrosequencing and direct sequencing analysis (table 1). Since the patient had previously undergone surgery for cutane-

results of their first HRM analyses. $-\mathrm{d}(\mathrm{RFU}) / \mathrm{dT}=$ Negative derivative $(-d)$ of relative fluorescence units (RFU) over temperature (dT). a The green and the red curves refer to the negative (wildtype) and to the $B R A F \mathrm{~V} 600 \mathrm{E}+$ control, respectively. b-d Melting profiles obtained in May 2014, of BRAF- samples that were analyzed by HRM for the first time in April 2012 (b), April 2013 (c) and April 2014 (d), respectively.

ous melanoma, a possible confounding effect of a $B R A F-$ mutated cutaneous neoplasia was excluded testing the melanoma histological specimen by pyrosequencing. The melanoma showed BRAF negativity. Considering these results and US features, a wait-and-see approach with US follow-up was considered appropriate for this patient.

Finally, sample 55 showed a hypoechoic nodule with ill-defined margins and intranodular vascularization. The FNAB sample was shown to be positive for BRAF V600E by HRM, but not by pyrosequencing. Direct sequencing revealed that $B R A F$ positivity was due to K601E rather than V600E mutation (table 1). Conversely, wFNAB was positive with all three methods. In particular, 
Table 1. Characteristics of THY2 and THY3 cytological samples with BRAF mutation positivity at HRM on wFNAB compared to HRM on FNAB, pyrosequencing and direct sequencing on wFNAB and FNAB

\begin{tabular}{|c|c|c|c|c|c|c|c|c|}
\hline ID & $\begin{array}{l}\text { Size, } \\
\mathrm{mm}\end{array}$ & $\begin{array}{l}\text { Suspicious } \\
\text { on US }\end{array}$ & Cyt. & $\begin{array}{l}B R A F \text { by } \\
\text { HRM on } \\
\text { wFNAB/sFNAB }\end{array}$ & $\begin{array}{l}B R A F \text { by } \\
\text { pyrosequencing on } \\
\text { wFNAB/sFNAB }\end{array}$ & $\begin{array}{l}B R A F \text { by direct } \\
\text { sequencing on } \\
\text { wFNAB/sFNAB }\end{array}$ & Histology & Stage \\
\hline s2 & 21 & Yes & THY2 & V600E+/n.a. & n.a./V600E+ & n.a. & Partially cystic PTC & pT2NxMx \\
\hline s3 & 6 & No & THY2 & V600E+/n.a. & n.a./V600E+ & n.a. & Classical variant of PTC & pT3mN1bMx \\
\hline s4 & 11 & No & THY2 & $\mathrm{V} 600 \mathrm{E}+/ \mathrm{WT}$ & WT/WT & WT/WT & No surgery & n.a. \\
\hline s7 & 13 & Yes & THY3 & V600E+ & n.a. & n.a. & $\begin{array}{l}\text { Classical and follicular } \\
\text { variant of PTC }\end{array}$ & pT1bNxMx \\
\hline
\end{tabular}

Cyt. = Cytology; ID = identification number; $\mathrm{mPTC}=$ micropapillary thyroid carcinoma; $\mathrm{THY} 2=$ benign; $\mathrm{THY} 3=$ indeterminate; $\mathrm{sF}-$ $\mathrm{NAB}=$ scraped cell DNA from FNAB slides; WT = wild-type; + = positive for the mutation;. .. = not assessed.

pyrosequencing and direct sequencing attributed $B R A F$ positivity to K601E rather than the V600E mutation. The positive BRAF mutational status, together with the US characteristics, recommended a surgical treatment. The molecular analysis, performed on the surgical sample by pyrosequencing, confirmed the presence of the BRAF K601E mutation, and the histological analysis documented a follicular variant of PTC.

Among THY3, HRM detected the BRAF V600E mutation in 2 wFNAB samples (s6 and s7; table 1). Both nodules (s6 and s7) had also US features suspicious for malignancy (markedly hypoechoic), and both patients underwent surgery resulting in a classical variant of PTC (s6) and follicular and classic variants of PTC (s7). The a posteriori review of sample $\mathrm{s} 7$ by the cytopathologist resulted in a reclassification into THY4 (suspicious for PTC).

Finally, HRM detected the BRAF V600E mutation in 6/9 THY4 and in 6/8 THY5 samples. In all these patients the histology confirmed the diagnosis of PTC.

Comparing the three different techniques, direct sequencing, pyrosequencing and HRM, and comparing the positive results of HRM analysis with the histological results, we can assert that we did not have false-positive results.

However, we do not have data regarding the $\mathrm{FN}$ rate of HRM analysis. Nevertheless, considering that pyrosequencing and HRM sensitivity is similar, we suppose that their FN rate is approximately the same.

\section{Diagnostic Value of BRAF HRM Analysis on wFNAB}

Based on history, clinical evaluation, US features and biochemical analyses, only 74 of the 481 patients underwent thyroid surgery providing histology outcome on a total of 94 nodules for which also the cytological analysis was available (table 2). In this subgroup, the addition of the BRAF analysis on wFNAB (obtained by HRM) to the cytological analysis improved sensitivity (from 43.6 to $59.0 \%$ ) and the positive predictive value (from 43.6 to $100 \%)$ of the presurgical diagnostic procedures. The accuracy of cytology alone and cytology plus $B R A F$ on wFNAB was 76.6 and $81.8 \%$, respectively. Cytology combined with BRAF resulted in a better performance of USassisted FNAB as far as the 'rule-in' approach is concerned, without any improvement of the 'rule-out' approach.

\section{Discussion}

The novelty of this study lies in the application of the powerful, highly sensitive, low-cost and easy-to-perform molecular analysis technique of HRM on wFNAB samples collected during routine clinical practice.

The validation of this technique allows collecting leftover cells in the needle without a further ad hoc FNAB. Compared to traditional procedures requiring 2 different FNABs for molecular and cytological analyses [16-18], the advantages of wFNAB are: (i) the certainty that both the material for molecular and cytological analyses derives from the same nodule; (ii) reduction of the patient's discomfort; (iii) procedural saving time (only 1 neck puncture); (iv) a more accurate diagnosis; (v) a posteriori analysis only in case of indeterminate cytology and/or other clinical indications (i.e. suspicious US features) after wFNAB storage. Besides, HRM on wFNAB seems to be further cost-saving. Differently from other wFNAB techniques $[14,19,20]$, in fact, the use of saline for storing 
Table 2. Diagnostic value of cytology alone and cytology combined with HRM/BRAF analysis on wFNAB compared with histology in the subgroup of patients $(n=74)$ who underwent thyroid surgery

a Cytology

\begin{tabular}{llccc}
\hline Cytological category & $\begin{array}{l}\text { Nodules with } \\
\text { histology/total, } \mathrm{n}(\%)\end{array}$ & $\begin{array}{l}\text { Benign histology, } \\
\mathrm{n}\end{array}$ & $\begin{array}{l}\text { Malignant histology, } \\
\mathrm{n}\end{array}$ & $\begin{array}{l}\text { wFNAB BRAF+ by HRM, } \\
\mathrm{n}\end{array}$ \\
\hline THY1 & $5 / 136(3.7)$ & 4 & 1 & 0 \\
THY2 & $25 / 415(6.0)$ & 17 & 8 & 4 \\
THY3 & $47 / 80(58.7)$ & 34 & 13 & 2 \\
THY4 & $9 / 9(100)$ & 0 & 9 & 6 \\
THY5 & $8 / 8(100)$ & 0 & 8 & 6 \\
\hline
\end{tabular}

b Overall diagnostic value of US-FNAB procedures

\begin{tabular}{|c|c|c|c|c|}
\hline & Sensitivity, \% & Specificity, \% & PPV, \% & NPV, \% \\
\hline $\begin{array}{l}\text { Cytology alone } \\
\text { Cytology }+B R A F \text { on }\end{array}$ & 43.6 & 100 & 43.6 & 71.4 \\
\hline
\end{tabular}

BRAF + = Positivity of BRAF mutation by HRM; THY1 = nondiagnostic; THY2 = benign; THY $3=$ indeterminate; THY4 = suspicious for malignancy; THY5 = diagnostic of malignancy; US-FNAB = ultrasound-assisted fine needle aspiration biopsy; sensitivity = number of true positives divided by the number of true positives plus the number of false negatives; specificity = number of true negatives divided by the number of true negatives plus the number of false positives; PPV = positive predictive value (number of true positives divided by the number of true positives plus the number of false positives); NPV = negative predictive value (number of true negatives divided by the number of true negatives plus the number of false negatives).

FNAB leftover cells is less expensive than preservative solutions $[16,18,19]$ and allows storing samples for long. Moreover, HRM is more sensitive and faster than DNA sequencing and both less expensive and time saving than direct sequencing and pyrosequencing, respectively. Accordingly, the entire procedure costs about EUR 7.50 and requires half and one third of the time compared to pyrosequencing and direct sequencing, respectively.

Differently from previous studies involving subjects with documented malignant [21] or indeterminate cytological diagnosis [16], in this study all patients were prospectively enrolled regardless of their cytological categories (THY1-THY5). Even the analysis of the small subgroup of patients who underwent surgery covers all the cytological categories and suggests that the diagnostic value of FNAB is improved by the addition of $B R A F$ analysis on HRM, as previously suggested by using different molecular techniques $[7,22]$. However, larger prospective studies, aimed at defining the 'number needed to diagnose', are required to provide information on the real effectiveness of this molecular diagnosis in thyroid cancer patients.

Among THY2 samples, the BRAF+ rate (1.2\%) was higher than in previous studies [20,23], but concordant with the known estimated risk of malignancy of $0-3 \%$
[24]. Cytological FN rates are underestimated in the THY2 category since histological verification is not always available since patients rarely undergo thyroidectomy. FN results in the THY2 category might depend on the cytopathologist's experience, sampling errors (e.g. FNAB within healthy thyroid rather than nodular tissue) or microcarcinoma [25]. In thyroid nodules greater than $4 \mathrm{~cm}$, FNAB might be not representative of the entire lesion resulting in an increased FN rate (about 13\%) [26]. Thus, the overall FN rate in THY2 ranges from 3 to $13 \%$ in different settings $[22,27]$ and accounts for a relevant number of misdiagnoses in consideration of the considerable prevalence of THY2 nodules [23]. Again, HRM molecular analysis on wFNAB reduced the FN rate in 4 THY2 nodules that were BRAF+ and improved the diagnostic value of cytology alone (table 2).

In addition, HRM seems to work even in detecting mutations in DNA positions close to the classic V600E mutation since, correctly identified as $B R A F+$, patient 5 (table 1) carried the rare BRAF mutation K601E in a follicular variant of PTC; the latter is known to be associated with the K601E mutation [28-30].

The BRAF V600E mutation was detected only in 2 out of 80 THY3 nodules $(2.5 \%)$, a rate similar to that (about 
$1.5 \%)$ of previous studies [16]. Thus, HRM on wFNAB coupled to cytology might be useful for better selecting patients deserving surgery among those with indeterminate nodules. As THY 3 nodules were shown to be benign at histology in $70-80 \%$ of cases [31], unnecessary surgery should be avoided.

No $B R A F$ mutation was found in inadequate samples even though the possibility of $B R A F$ positivity cannot be completely ruled out in THY1 $[20,22]$. Differently from previous reports [32], in our hands HRM is a valid methodology also in samples characterized by poor cellularity ( $<6$ clusters of 10 cells/group).

In clinical practice, several characteristics make HRM on wFNAB an ideal procedure to be introduced in a routine diagnostic setting as an adjunct to cytology [17, 22, $33,34]$. In particular, HRM on wFNAB is feasible and allows saving of time, financial resources and human efforts especially when used in an a posteriori approach. This sort of 'BRAF reflex' could be useful especially in case of suspicious nodules on US, cytologically classified as benign or indeterminate since it improves the diagnostic value of cytology alone, resulting in early cancer diagnosis and a more appropriate indication for surgery (e.g. central neck compartment) in FN nodules. Further costs due to inappropriate surgery in indeterminate nodules and the reoperation after lobectomy for thyroid cancer might also be avoided. This cost-effectiveness of $B R A F$ analysis has already been demonstrated also by using $B R A F$ assays which are more expensive than HRM [7, 34].

Furthermore, the HRM approach could include analysis of other discrete point mutations related to thyroid cancer (e.g. RAS), extending its diagnostic performance.
A possible interesting molecular analysis regards the mutations in the telomerase reverse transcriptase. The inclusion of telomerase reverse transcriptase promoter mutations in the molecular analysis of FNABs allows a better preoperative risk stratification, especially when coupled with BRAF analysis [35].

In conclusion, the development of less expensive, highly sensitive methods for $B R A F$ assays allows improving the cost-effectiveness of molecular analyses coupled to $\mathrm{FNAB}$, a prerequisite for introducing these tests in the routine workout for the diagnosis of thyroid nodules, especially in geographic areas where the frequency of $B R A F$ mutations is not high [36].

HRM analysis on wFNAB represents a valid and sustainable procedure for large-scale $B R A F$ analysis useful to help the clinician's decision-making in THY2 and THY3 nodules, especially when suspicious US features are present.

\section{Acknowledgments}

This study was supported by institutional funds of the Unit of Endocrinology of the University of Modena and Reggio Emilia. Marco Marino is recipient of a SPINNER 2013 fellowship of the region Emilia Romagna (contract No. 076/13).

\section{Disclosure Statement}

The authors declare that there is no conflict of interests that could be perceived as prejudicing the impartiality of the research reported.

\section{References}

1 Xing M: BRAF mutation in thyroid cancer. Endocr Relat Cancer 2005;12:245-262.

-2 Davies H, Bignell GR, Cox C, Stephens P, Edkins S, Clegg S, Teague J, Woffendin H, Garnett MJ, Bottomley W, Davis N, Dicks E, Ewing R, Floyd Y, Gray K, Hall S, Hawes R, Hughes J, Kosmidou V, Menzies A, Mould C, Parker A, Stevens C, Watt S, Hooper S, Wilson R, Jayatilake H, Gusterson BA, Cooper C, Shipley J, Hargrave D, Pritchard-Jones K, Maitland N, Chenevix-Trench G, Riggins GJ, Bigner DD, Palmieri G, Cossu A, Flanagan A, Nicholson A, Ho JW, Leung SY, Yuen ST, Weber BL, Seigler HF, Darrow TL, Paterson H, Marais R, Marshall CJ, Wooster R, Stratton MR, Futreal PA: Mutations of the BRAF gene in human cancer. Nature 2002;417:949-954.

-3 Kimura ET, Nikiforova MN, Zhu Z, KnaufJA, Nikiforov YE, Fagin JA: High prevalence of
BRAF mutations in thyroid cancer: genetic evidence for constitutive activation of the RET/PTC-RAS-BRAF signalling pathway in papillary thyroid carcinoma. Cancer Res 2003;63:1454-1457.

4 Xing M: BRAF mutation in papillary thyroid cancer: pathogenic role, molecular bases, and clinical implications. Endocr Rev 2007;28: 742-762.

5 Ito Y, Nikiforov YE, Schlumberger M, Vigneri R: Increasing incidence of thyroid cancer: controversies explored. Nat Rev Endocrinol 2013;9:178-184.

6 Hegedüs L: Clinical practice: the thyroid nodule. N Engl J Med 2004;351:1764-1771.

7 Eszlinger M, Hegedüs L, Paschke R: Ruling in or ruling out thyroid malignancy by molecular diagnostics of thyroid nodules. Best Pract Res Clin Endocrinol Metab 2014;28:545-557.
-8 Cooper DS, Doherty GM, Haugen BR, Kloos RT, Lee SL, Mandel SJ, Mazzaferri EL, McIver B, Pacini F, Schlumberger M, Sherman SI, Steward DL, Tuttle RM: Revised American Thyroid Association management guidelines for patients with thyroid nodules and differentiated thyroid cancer. Thyroid 2009;19: 1167-1214.

\9 Kim SW, Lee JI, Kim JW, Ki CS, Oh YL, Choi YL, Shin JH, Kim HK, Jang HW, Chung JH: $B R A F \mathrm{~V} 600 \mathrm{E}$ mutation analysis in fine-needle aspiration cytology specimens for evaluation of thyroid nodule: a large series in a $B R A F$ V600E-prevalent population. J Clin Endocrinol Metab 2010;95:3693-3700.

10 Melck AL, Yip L, Carty SE: The utility of $B R A F$ testing in the management of papillary thyroid cancer. Oncologist 2010;15:12851293. 
$\checkmark 11$ Lee HJ, Choi J, Hwang TS, Shong YK, Hong SJ, Gong G: Detection of BRAF mutations in thyroid nodules by allele-specific PCR using a dual priming oligonucleotide system. Am J Clin Pathol 2010;133:802-808.

$\checkmark 12$ Kim SK, Kim DL, Han HS, Kim WS, Kim SJ, Moon WJ, Oh SY, Hwang TS: Pyrosequencing analysis for detection of a $B R A F \mathrm{~V} 600 \mathrm{E}$ mutation in an FNAB specimen of thyroid nodules. Diagn Mol Pathol 2008;17:118125 .

$\checkmark 13$ Moon HJ, Kim EK, Chung WY, Choi JR, Yoon JH, Kwak JY: Diagnostic value of BRAF (V600E) mutation analysis of thyroid nodules according to ultrasonographic features and the time of aspiration. Ann Surg Oncol 2011; 18:792-799.

14 Di Benedetto G, Fabozzi A, Rinaldi C, Rinaldi CR: BRAF test and cytological diagnosis with a single fine needle cytology sample. Acta $\mathrm{Cy}$ tol 2013;57:337-340.

$\checkmark 15$ Koh J, Choi JR, Han KH, Kim EK, Yoon JH, Moon HJ, Kwak JY: Proper indication of $B R A F$ (V600E) mutation testing in fine-needle aspirates of thyroid nodules. PLoS One 2013;8:e64505.

-16 Nikiforov YE, Ohori NP, Hodak SP, Carty SE, LeBeau SO, Ferris RL, Yip L, Seethala RR, Tublin ME, Stang MT, Coyne C, Johnson JT, Stewart AF, Nikiforova MN: Impact of mutational testing on the diagnosis and management of patients with cytologically indeterminate thyroid nodules: a prospective analysis of 1,056 FNA samples. J Clin Endocrinol Metab 2011;96:3390-3397.

-17 Hodak SP, Rosenthal DS: Information for clinicians: commercially available molecular diagnosis testing in the evaluation of thyroid nodule fine-needle aspiration specimens. American Thyroid Association Clinical Affairs Committee. Thyroid 2013 23:131-134

18 Nikiforov YE, Steward DL, Robinson-Smith TM, Haugen BR, Klopper JP, Zhu Z, Fagin JA, Falciglia M, Weber K, Nikiforova MN: Molecular testing for mutations in improving the fine-needle aspiration diagnosis of thyroid nodules. J Clin Endocrinol Metab 2009;94: 2092-2098.

19 Chang H, Lee H, Yoon SO, Kim H, Kim A, Kim BH: BRAF (V600E) mutation analysis of liquid-based preparation-processed fine needle aspiration sample improves the diagnostic rate of papillary thyroid carcinoma. Hum Pathol 2012;43:89-95.

20 Cañadas-Garre M, Becerra-Massare P, López de la Torre-Casares M, Villar-del Moral J, Céspedes-Mas S, Vílchez-Joya R, Muros-de Fuentes T, García-Calvente C, Piédrola-Maroto G, López-Nevot MA, Montes-Ramírez R, Llamas-Elvira JM: Reduction of false-negative papillary thyroid carcinomas by the routine analysis of BRAF (T1799A) mutation on fine-needle aspiration biopsy specimens: a prospective study of 814 thyroid FNAB patients. Ann Surg 2012;255:986-992.

21 Joo JY, Park JY, Yoon YH, Choi B, Kim JM, Jo YS, Shong M, Koo BS: Prediction of occult central lymph node metastasis in papillary thyroid carcinoma by preoperative $B R A F$ analysis using fine-needle aspiration biopsy: a prospective study. J Clin Endocrinol Metab 2012;97:3996-4003.

22 Eszlinger M, Piana S, Moll A, Bösenberg E, Bisagni A, Ciarrocchi A, Ragazzi M, Paschke R: Molecular testing of thyroid fine-needle aspirations improves presurgical diagnosis and supports the histologic identification of minimally invasive follicular thyroid carcinomas. Thyroid. 2015;25:401-409.

23 Proietti A, Borrelli N, Giannini R, Romani R, Di Coscio G, Quilici F, Rago T, Miccoli P, Vitti P, Basolo F: Molecular characterization of 54 cases of false-negative fine-needle aspiration among 1,347 papillary thyroid carcinomas. Cancer Cytopathol 2014;122:751759.

24 Cibas ES, Ali SZ: NCI thyroid FNA state of the science conference. The Bethesda system for reporting thyroid cytopathology. Am J Clin Pathol 2009;132:658-665.

25 Hambleton C, Kandil E: Appropriate and accurate diagnosis of thyroid nodules: a review of thyroid fine-needle aspiration. Int J Clin Exp Med 2013;6:413-422.

26 McCoy KL, Jabbour N, Ogilvie JB, Ohori NP, Carty SE, Yim JH: The incidence of cancer and rate of false-negative cytology in thyroid nodules greater than or equal to $4 \mathrm{~cm}$ in size. Surgery 2007;142:837-844.

27 Wang CC, Friedman L, Kennedy GC, Wang H, Kebebew E, Steward DL, Zeiger MA, Wes- tra WH, Wang Y, Khanafshar E, Fellegara G, Rosai J, Livolsi V, Lanman RB: A large multicenter correlation study of thyroid nodule cytopathology and histopathology. Thyroid 2011;21:243-251.

28 Pennelli G, Vianello F, Barollo S, Pezzani R, Merante Boschin I, Pelizzo MR, Mantero F, Rugge M, Mian C: BRAF(K601E) mutation in a patient with a follicular thyroid carcinoma. Thyroid 2011;21:1393-1396.

29 Park JY, Kim WY, Hwang TS, Lee SS, Kim H, Han HS, Lim SD, Kim WS, Yoo YB, Park KS: $B R A F$ and $R A S$ mutations in follicular variants of papillary thyroid carcinoma. Endocr Pathol 2013;24:69-76.

30 Barollo S, Pezzani R, Cristiani A, Redaelli M, Zambonin L, Rubin B, Bertazza L, Zane M, Mucignat-Caretta C, Bulfone A, Pennelli G, Casal Ide E, Pelizzo MR, Mantero F, Moro S, Mian C: Prevalence, tumorigenic role, and biochemical implications of rare $B R A F$ alterations. Thyroid 2014;24:809-819.

31 Castro MR, Gharib H: Thyroid fine-needle aspiration biopsy: progress, practice, and pitfalls. Endocr Pract 2003;9:128-136.

32 Dyhdalo K, Macnamara S, Brainard J, Underwood D, Tubbs R, Yang B: Assessment of cellularity, genomic DNA yields, and technical platforms for BRAF mutational testing in thyroid fine-needle aspirate samples. Cancer $\mathrm{Cy}$ topathol 2014;122:114-122.

33 Poller DN, Glaysher S, Agrawal A, Caldera S, Kim D, Yiangou C: BRAF V600 co-testing in thyroid FNA cytology: short-term experience in a large cancer centre in the UK. J Clin Pathol 2014;67:684-689.

34 Yip L, Farris C, Kabaker AS, Hodak SP, Nikiforova MN, McCoy KL, Stang MT, Smith KJ, Nikiforov YE, Carty SE: Cost impact of molecular testing for indeterminate thyroid nodule fine-needle aspiration biopsies. J Clin Endocrinol Metab 2012;97:1905-1912.

35 Liu R, Xing M: Diagnostic and prognostic TERT promoter mutations in thyroid fineneedle aspiration biopsy. Endocr Relat Cancer 2014;21:825-830.

36 Pacini F, Castagna MG, Brilli L, Pentheroudakis G; ESMO Guidelines Working Group: Thyroid cancer: ESMO Clinical Practice Guidelines for diagnosis, treatment and follow-up. Ann Oncol 2012;23:110-119. 